\title{
The Estimate of Fault Location based on Transmission Tower Coordinates
}

\author{
Azriyenni Azhari Zakri*, Wenny Dwi Tristiyanti and Salhazan Nasution \\ Department of Electrical Engineering, Faculty of Engineering, Universitas Riau, Kampus Bina Widya, \\ Pekanbaru 28293, Indonesia
}

("Corresponding author's e-mail: azriyenni@eng.unri.ac.id)

Received: 16 October 2020, Revised: 11 May 2021, Accepted: 16 May 2021

\begin{abstract}
This study was conducted to predict the fault location based on tower coordinates using the Artificial Neural Network (ANN). The electrical power system modeled made use of an actual system including 150 $\mathrm{kV}$ transmission line with KP bus to the GS bus and $64 \mathrm{~km}$ length while ANN technique was used to coordinate the points for the fault location on the electric power transmission line due to its ability to predict what will happen in the future based on the pattern of past events. The ANN was tested and trained at certain iterations with different data which were simulated for short circuit fault type at several locations to achieve the best value. The results obtained with fault location coordinates were in the form of latitude and longitude while the simulation results for the AG fault were at $0.0381 \mathrm{~km}$ distance starting from the KP bus to the GS bus at 8,246 kA. Moreover, the estimated error values were found in the 2-phase fault to the ground at $4.01 \times 10^{-3} \%$ while the ANN structure performance showed the MSE value to be $2.08-4 \%$ with a very small error value of $0.57 \%$ and this means it is included in the existing standard tolerance category. The data validation of this system modeling was conducted on the short circuit current value between simulation and theoretical estimation.
\end{abstract}

Keywords: Artificial neural network, Estimation, Transmission line, Tower coordinates

\section{Introduction}

The transmission line is a very important part of transmitting electrical power to a load and the existence of any fault in the line leads to disconnection and losses for consumers which means it needs sustainable maintenance. The most frequent fault often observed in these lines is in the form of the asymmetrical and symmetrical short circuit [1] which have different characteristics, both in current and voltage [2]. This means there is a need to understand the type of short circuit fault in order to determine the best way to handle it. Therefore, this research aimed to predict the fault location based on the distance and coordinates of the transmission tower. The faults were monitored using the distance in length units while the coordinate points determined the geographic coordinate system in the form of latitude and longitude.

Several methods have been applied to determine the location of faults on a power transmission line and an example of these methods is the Phasor Measurement Unit (PMU) which is part of the current and voltage values in the control center while the application system uses IEEE 9-bus $[3,4]$. Some other hybrid techniques which have been implemented include Discrete Wavelet Transformation (DWT) and Support Vector Machine (SVM) [5,6] as well as several others applied in electric power transmission lines. Moreover, fault diagnosis has been monitored in Wide Area System using the Phasor Measurement Unit (PMU) with measurements conducted by monitoring, controlling, and protecting as well as through the combination of the functions of the phasor measuring device [4,7] while the fault in hybrid electrical network is usually detected based on GPS and PMU [8-10]. The 3-phase faults in electrical power distribution networks are detected through a combination of discrete variables and Particle Swarm Optimization (PSO) while the proposed algorithm has been reported to be accurate to estimate the magnitude and angle of the network bus voltage [11].

Several studies have also discussed the prediction of faults location on transmission lines [12,13] with Artificial Neural Network (ANN) Techniques and Statistical Synchronous Compensator (STATCOM) designed for multiple circuit transmission lines using $300 \mathrm{~km}$ long line, $500 \mathrm{kV}$ voltage, and $60 \mathrm{~Hz}$ frequency. The fundamental voltage and current signal at the end of the channel were extracted using 
Fourier Discrete Transformations and later trained using ANN with the Levenberg Marquardt algorithm after which the data were tested for different faults and error value calculated [14].

Uzubi et al. [15] diagnosed faults location on transmission lines in Nigeria to evaluate the relay performance based on the ANN technique connected to both ends of the channel using backpropagation and Levenberg Marquardt algorithm while the fault data were analyzed using PSCAD/EMTP software. The transmission line made use of $132 \mathrm{kV}$ voltage source with several variations in the starting angle, location, and fault resistance while the fault current was extracted and processed and the data trained and tested using MATLAB/Simulink software. Ahmed Sabri A and Johnson A researched the fault location in high voltage transmission lines with the data trained as well as the types and locations of faults tested and verified using ANN algorithm while validation was conducted by varying the actual network data using MATLAB/Simulink [16].

This article aimed to predict the fault location based on the distance and coordinates of the transmission tower while the success of the predictions was tested using the ANN techniques to produce good results and recognize the previously trained patterns. The output from the ANN output is the coordinate points used in determining the fault location on a real map through the ArcGIS/ArcMap application. Moreover, every channel has 199 supporting poles which are 200 - $390 \mathrm{~m}$ apart while the data retrieved were used to model transmission line systems with different types of short circuit faults.

\section{Materials and methods}

ANN technique was used to classify data with several variables by training or learning the data to map input and output relationships due to its ability to predict future occurrences based on the pattern of past events. The training model is said to be successful in convergent training and fail in divergent training. Meanwhile, convergence is achieved when the error in every training iteration decreases continuously to the point where the weight value for each neuron reaches the best for the data provided. Conversely, divergence is attained when the error does not tend to decrease to a certain point $[6,17,18]$.

Several types of short circuit faults are simulated on single-phase grounds (AG, BG, CG), 2-phase grounds (ABG, ACG, BCG), interphases (AB, AC, BC), and three-phase faults (ABC) $[7,11,19]$ while Figure 2 shows the ANN estimation block diagram for the fault location coordinates. Moreover, the model was built with different locations consisting of data obtained from short circuit fault simulation in the form of normalized fault voltage and current signal. The normalization was used as the ANN input to estimate the coordinates of fault location while the electric power transmission system applied as a model is the transmission from KP and GS buses in Riau Province, Indonesia with its 3 power generation units illustrated in Figure 1. Furthermore, the KP buses receive the power of $136 \mathrm{MW}$ from the PYK buses with each bus in the system having a different load while the short circuit fault was placed on the $64 \mathrm{~km}$ transmission line between KP and GS buses.

The input and target data in ANN process, the actual system modeling of the electric power of the KP bus to the GS Bus have been performed using MATLAB/Simulink software. Short circuit fault simulation run has a distance value of the fault location based on the coordinates of the transmission tower. A model built based on data dated October 1, 2017, it is necessary in order to verify by checking the value of the fault current parameter. The verification result is conducted on a single-phase short circuit to ground. That is located in phase $\mathrm{A}$, where the fault time is $2 / 50$, and fault resistance is $4.36 \Omega$. The RMS voltage in phase $\mathrm{A}$ at the fault location is $24,656.8 \mathrm{~V}$ in simulation performance. Then, the RMS voltage in phase A at the same fault location is $27,706 \mathrm{~V}$ in calculating.

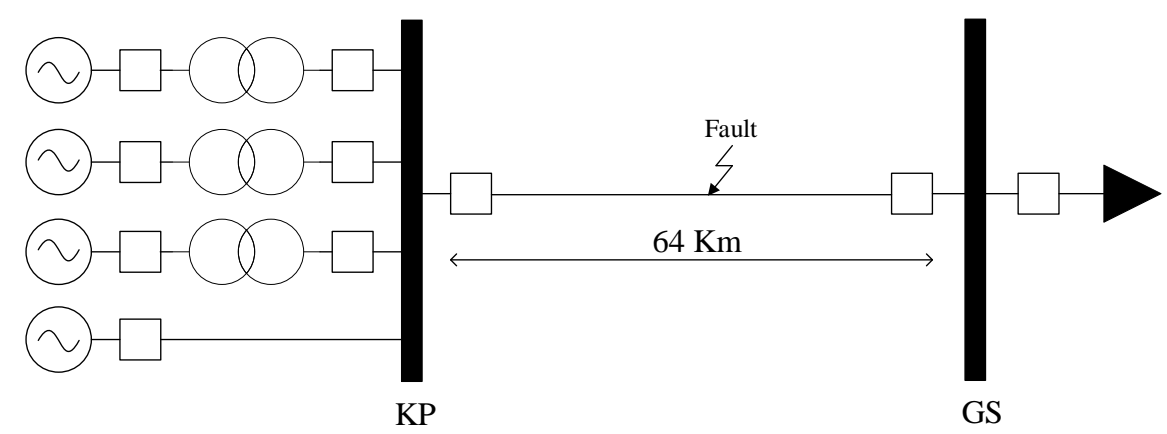

Figure 1 Single line diagram of KP to GS bus transmission system. 
Short circuit faults were simulated on the transmission line from KP to GS bus and modeled for each phase repeatedly using different fault locations. The simulation was conducted to retrieve fault data to be used as input for the ANN training and testing while the Haversine Theorem was applied to determine the distance between 2 points through the estimation of a plane with curvature degree [20,21]. This involved calculating the input point distance on the earth's surface in the form of latitude and longitude using radius $\mathrm{R}=64 \mathrm{~km}$. The Mean Square Error (MSE) is usually used to predict every failure. The sample experiment involves the complete modification of the real and analytical rates and a similar weight was observed in the differentiation of every information. The MSE equivalence of an aggregate of information were used to obtain inequality as shown in Eq. (1) [22].

$\operatorname{MSE}=\frac{\left|y_{i}-y_{i}^{\prime}\right|^{2}}{N}$

\section{ANN design for the coordinate point of fault location}

The coordinate for each fault type was designed to predict the fault location coordinates in the form of latitude and longitude in single-phase short circuit to ground (AG, BG, CG), 2-phase to ground (ABG, ACG, BCG), inter-phase ( $A B, A C, B C)$, and 3-phase (ABC) [5]. Figure 2 presents a block diagram of ANN to estimate the coordinates of the fault location, this is intended to estimate the coordinates of the type of fault in. The output is placed in coordinate points is latitude and longitude for the fault location. The fault types have been simulated for single-phase to ground (AG, BG, CG), 2-phase to ground (ABG, ACG, $\mathrm{BCG})$, inter-phase $(\mathrm{AB}, \mathrm{AC}, \mathrm{BC})$ and 3-phase $(\mathrm{ABC})$ short circuits.

The weight and standard bias of backpropagation is random numbers of small values, and the weight of the value of the small activation derivative. Techniques that can be used to initialize bias values and initial weight value in specified intervals. Before data are used as ANN input, the data are normalized first so that it is at the interval value 0 to 1 . Normalization can be used by following equation [23];

$N^{\prime}=\frac{N-\min }{\max -\min }\left(n e w_{\max }-n e w_{\min }\right)+n e w_{\min }$

The normalized value is used for the ANN input, and the ANN output in the latitude and longitude coordinate values is denormalized to the actual value. Denormalization is also performed to change the normalized value to its true value. This method can be used with the following min-max technique [24];

$x=\frac{\left(x^{\prime}-0.1\right)\left(x_{\max }-x_{\min }\right)}{0.8}+x_{\min }$

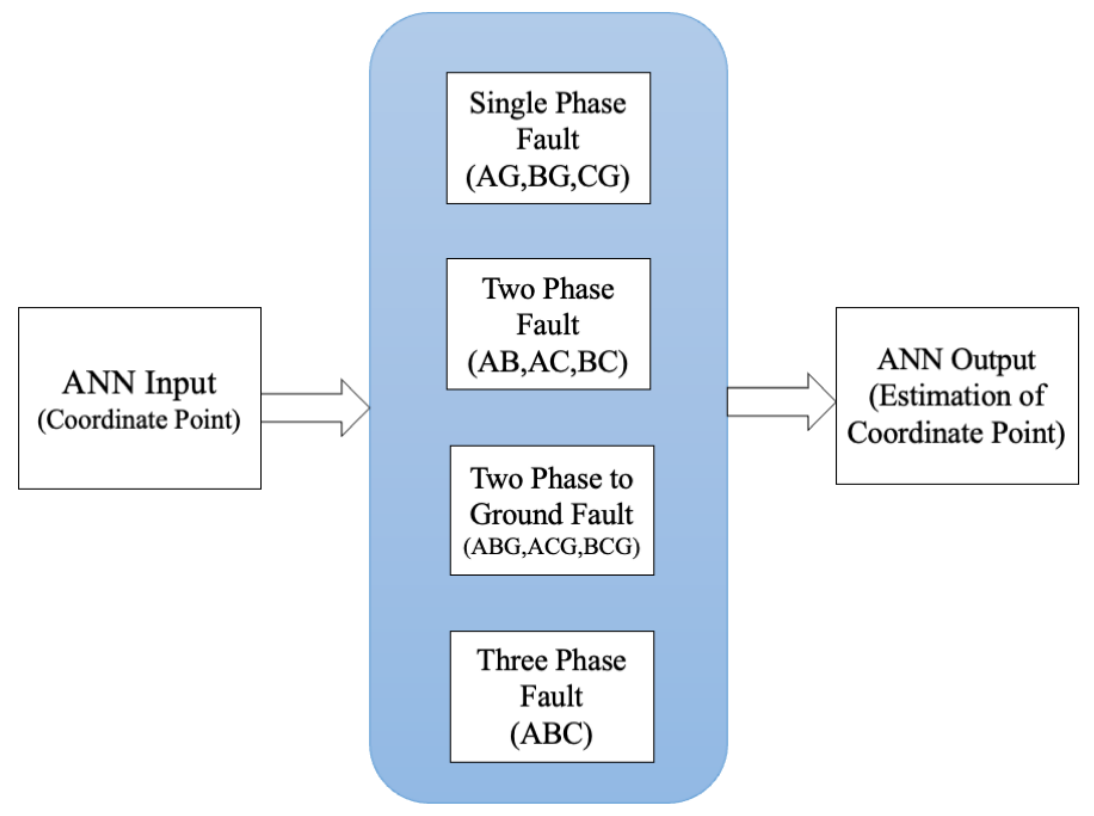

Figure 2 ANN block diagram for estimation of coordinate point. 
Figure 3 shows the ANN estimation block diagram for the fault location coordinates with the activation function such as binary sigmoid. According to Figure 3, the ANN structure for the first layer has 7 neurons to receive input which are the normalized peak values of current and voltage in phases, A, B, C as well as a zero-sequence current peak values, while the hidden layer has 3 parts with the first consisting of 50 neurons, the second, 40, and the third, 30 .

The ANN output for the fault location obtained in the form of latitude and longitude coordinates were normalized to obtain the true values while a point shift was observed between the estimated and targeted coordinates to determine accuracy. Table 1 shows the training and testing data selected were 189 and 10 inputs respectively and used as the targets for the estimated ANN coordinates for the fault location. Moreover, the inputs used in the training and testing were in the form of peak current, voltage for each phase, and a normalized peak value of zero-sequence current. The ANN estimation output was the estimation of the latitude and longitude coordinates from the normalized fault location on the transmission line.

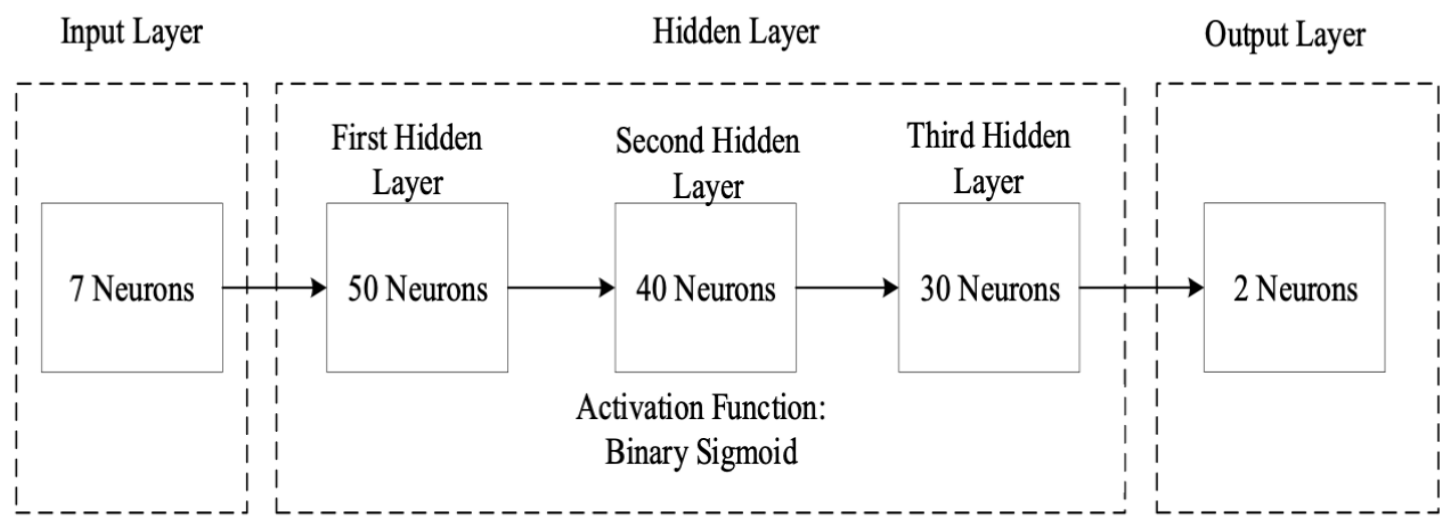

Figure 3 ANN Structure of coordinate point for fault location.

Table 1 Training \& testing data of short circuit fault.

\begin{tabular}{|c|c|c|}
\hline Data & Type of fault & Number of tower \\
\hline Training & $\begin{array}{c}\text { LG (AG, BG, CG) } \\
\text { LL (AB, AC, BC) } \\
\text { LLG (ABG, ACG, BCG) } \\
\text { LLL (ABC) }\end{array}$ & $\begin{array}{c}1,2,3,4,5, \ldots, 196,197,198,199 \\
\text { (189 towers) }\end{array}$ \\
\hline Testing & $\begin{array}{c}\text { LG (AG, BG, CG) } \\
\text { LL (AB, AC, BC) } \\
\text { LLG (ABG, ACG, BCG) } \\
\text { LLL (ABC) }\end{array}$ & $\begin{array}{c}10,30,50,70,90,110,130,150,170,190 \\
(10 \text { towers })\end{array}$ \\
\hline
\end{tabular}

\section{Results and discussion}

The simulation results from the ANN technique were used as the input and target data for the training and testing process while the electric power transmission system from KP and GS bus was modeled using the MATLAB/Simulink software. The short circuit fault simulation on the transmission line was a single phase to ground type based on the coordinates of the transmission tower, the results were normalized and later used input data and targets for training and testing to produce the results displayed in Table 2. The CG fault of the ANN model was found to have the longest training time of $57 \mathrm{~min} 38 \mathrm{~s}$ while the fastest at 20 min, $44 \mathrm{~s}$ was with AG fault.

Figure 4 shows the ANN output and target for the coordinates test of AG fault with the coordinate points marked with red circle while the target coordinates are in blue mark and the ANN output in orange. Table 3 shows the test results of the AG fault ANN model for 10 test coordinate data with 0.99 and 0.08575 $\%$ error percentage for both latitude and longitude. This MSE calculation is intended to evaluate the model run using the ANN method, so MSE is used to measure the amount of error. Figure 5(a) and 5(b) show the training and testing results of latitude and longitude coordinate data against the target and ANN output 
for AG fault. The ANN technique for the AG fault produced an MSE test of $5.43 \times 10^{-5}$ as indicated in Figure 5 while the estimated coordinates of the AG fault location are displayed on the actual map and compared with the target data. Moreover, Figure 6(a) shows the trained MSE applied to the ANN with the AG fault coordinate points and the highest MSE value was recorded at the beginning of the training and observed to have decreased to $10,000^{\text {th }}$ iteration after been trained. Figure $6(\mathbf{b})$ shows the $2.08 \times 10^{-4} \mathrm{MSE}$ value calculated from the ANN structure using the coordinate points for several fault types.

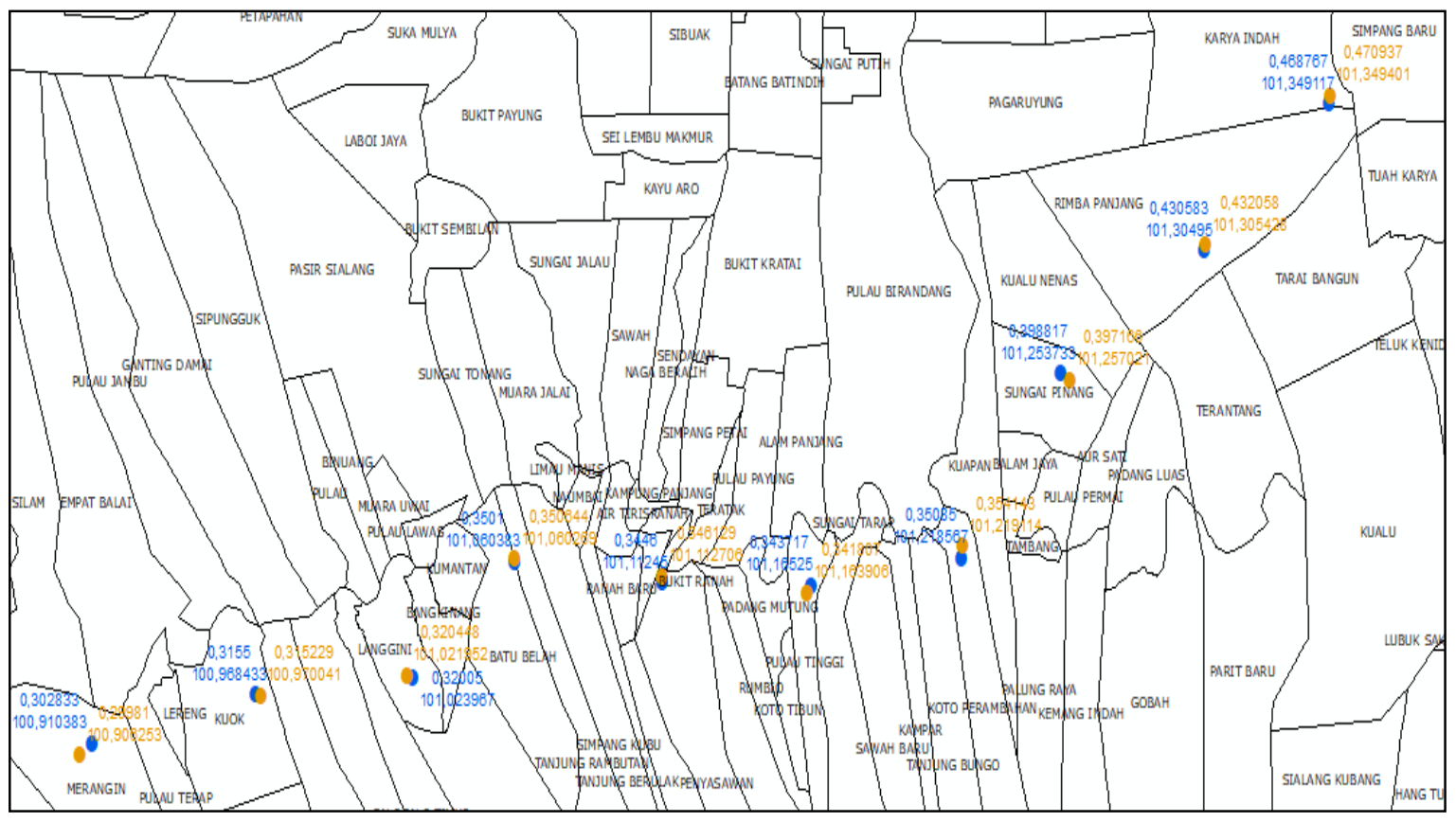

Figure 4 The test results output for the coordinates of AG fault.

Table 2 Results of ANN training for each type of short circuit fault.

\begin{tabular}{cccc}
\hline Model & Iteration & Duration of Training & MSE \\
\hline AG & 10,000 & $20 \mathrm{~m}: 44 \mathrm{~s}$ & 0.00002442 \\
BG & 10,000 & $24 \mathrm{~m}: 37 \mathrm{~s}$ & 0.00002491 \\
CG & 10,000 & $57 \mathrm{~m}: 38 \mathrm{~s}$ & 0.00007162 \\
ABG & 10,000 & $23 \mathrm{~m}: 0 \mathrm{~s}$ & 0.00002962 \\
ACG & 10,000 & $24 \mathrm{~m}: 17 \mathrm{~s}$ & 0.00002584 \\
BCG & 10,000 & $24 \mathrm{~m}: 33 \mathrm{~s}$ & 0.00002113 \\
AB & 10,000 & $36 \mathrm{~m}: 37 \mathrm{~s}$ & 0.00004354 \\
AC & 10,000 & $24 \mathrm{~m}: 22 \mathrm{~s}$ & 0.00001796 \\
BC & 10,000 & $24 \mathrm{~m}: 27 \mathrm{~s}$ & 0.00005446 \\
ABC & 10,000 & $25 \mathrm{~m}: 27 \mathrm{~s}$ & 0.00002171 \\
\hline
\end{tabular}

The test showed a shift value between the target coordinate point and estimate to be $0.55 \mathrm{~km}$ while the minimum shift was $0.06 \mathrm{~km}$. The ABG fault in ANN structure has the largest error percentage of $0.78527 \%$ while ACG has the smallest value of $4.01 \times 10^{-3} \%$ and the coordinate points for fault implemented include 7 neurons at the input and 2 neurons at the output. Meanwhile, the hidden layer has 3 parts with the first, second, and third layers having 50, 40, and 30 neurons respectively. Moreover, the value obtained for the short circuit current value from the simulation and theoretical calculations were validated after which they were compared and a very small error value of $0.57 \%$ was found. Therefore, means it is in the standard limited tolerance value. 
Table 3 ANN test results with coordinate points for the type of AG fault.

\begin{tabular}{ccc}
\hline Latitude & Longitude & Target and prediction coordinates \\
\hline $0.99819 \%$ & $0.00409 \%$ & 0.55 \\
$0.08575 \%$ & $0.00159 \%$ & 0.17 \\
$0.12448 \%$ & $0.00199 \%$ & 0.22 \\
$0.15545 \%$ & $0.00011 \%$ & 0.06 \\
$0.44378 \%$ & $0.00025 \%$ & 0.17 \\
$0.55555 \%$ & $0.00133 \%$ & 0.26 \\
$0.93865 \%$ & $0.00054 \%$ & 0.37 \\
$0.41390 \%$ & $0.00325 \%$ & 0.38 \\
$0.34242 \%$ & $0.00047 \%$ & 0.17 \\
$0.46305 \%$ & $0.00028 \%$ & 0.24 \\
\hline MSE & & $\mathbf{0 . 0 0 0 0 5 4 3}$ \\
\hline
\end{tabular}

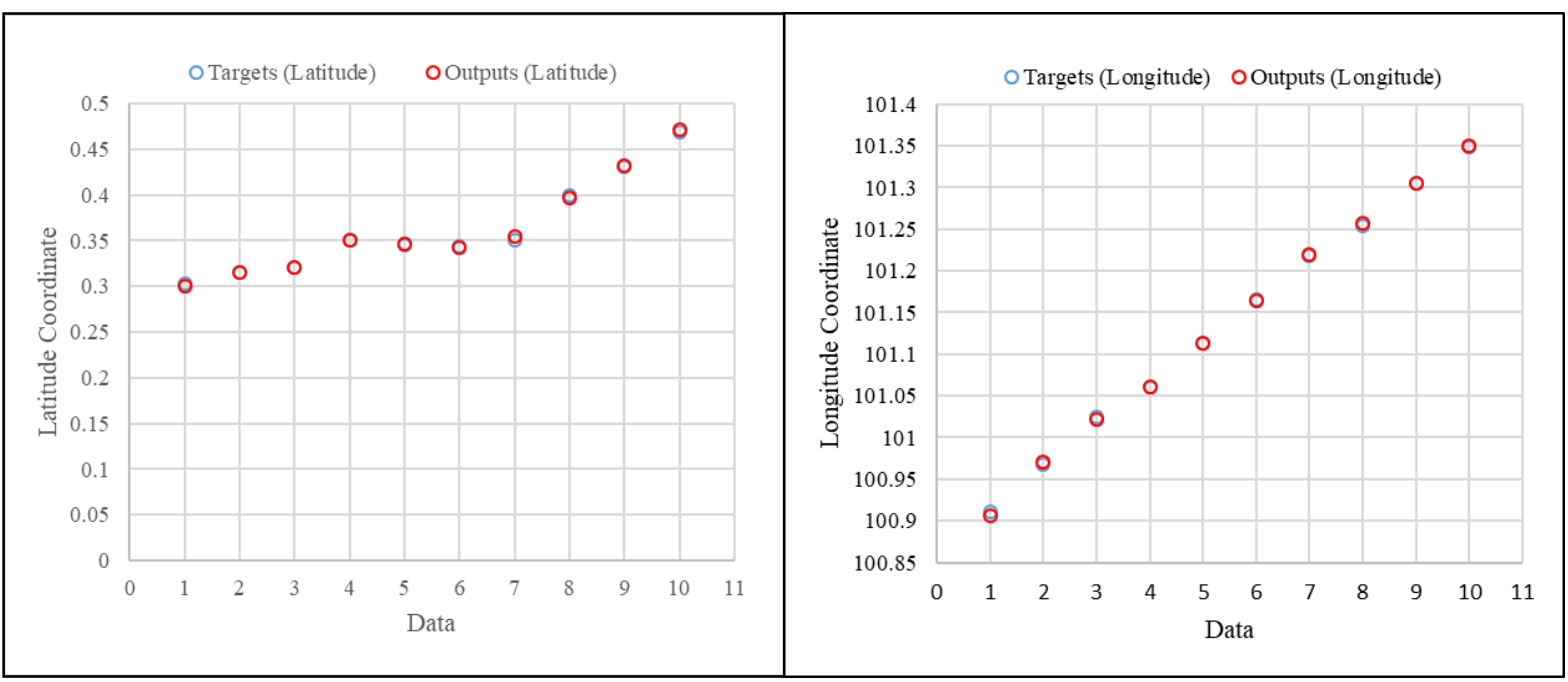

(a)

(b)

Figure 5 (a) ANN output with latitude coordinate point for AG fault type, and (b) ANN output with longitude coordinate point for AG fault type. 


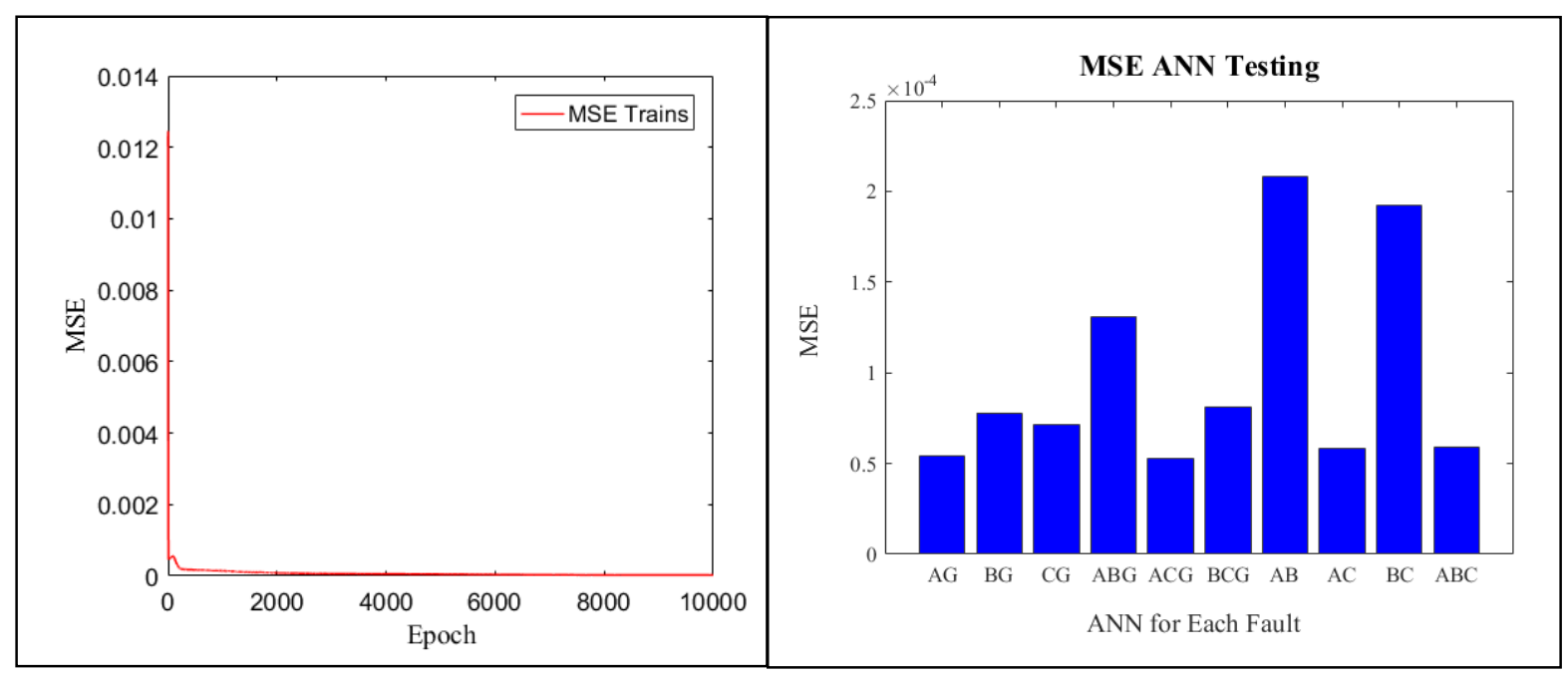

(a)

(b)

Figure 6 (a) MSE values trained using ANN for AG fault, and (b) Results of MSE calculations from ANN testing on fault types.

\section{Conclusions}

The ANN coordinates design and analysis was used to simulate some short circuit fault location in the electric power transmission system of KP and GS bus which was modeled and verified using a theoretical short circuit current value with $0.5681 \%$ error rate. In AG fault simulation, the short circuit current was observed at $0.0381 \mathrm{~km}$ from the 8,246 kA KP bus with the lowest at $64 \mathrm{~km}$ from the 2,997 kA KP bus. Moreover, the lowest error of $4.01 \times 10^{-3} \%$ was recorded with ACG fault while the highest, 0.78 $\%$, was found with $\mathrm{ABG}$ fault. After the ANN structure has been in operation with points for several types of fault, the MSE value obtained for ACG fault was $5.25 \times 10^{-5}$ while AB fault had $2.08 \times 10^{-4}$. The prediction of the fault location based on the distance and coordinates of the transmission towers has been tested using ANN techniques to develop alternative techniques with tower data. The pattern that has been developed for this transmission line can become a reference pattern for other cases.

\section{Acknowledgements}

The author would like to thank the Ministry of Research and Technology/National Research and Innovation Agency (RISTEK-BRIN), Republic of Indonesia, for providing financial support with contract number 399/UN.19.5.1.3/PT.01.03/2020.

\section{References}

[1] AA Zakri. Fault diagnosis for transmission lines systems using ANFIS technique. Int. J. Electr. Energ. Power Syst. Eng. 2018; 1, 17-21.

[2] R Bayindir, E Irmak, F Issi and N Guler. Short-circuit fault analysis on microgrid. In: Proceedings of the 2015 International Conference on Renewable Energy Research and Applications, Palermo, Italy. 2015, p. 1248-52.

[3] A Waqar, Z Khurshid, J Ahmad, M Aamir, M Yaqoob and I Alam. Modeling and simulation of phasor measurement unit (PMU) for early fault detection in interconnected two-area network. In: Proceedings of the $20181^{\text {st }}$ International Conference on Power, Energy and Smart Grid, Mirpur Azad Kashmir, Pakistan. 2018, p. 1-6.

[4] AA Zakri, MW Mustafa, H Syaibi and I Sofimieari. Monitoring fault diagnosis based on phasor measurement unit at wide area systems. In: Proceedings of the 2019 IEEE Conference on Energy Conversion, Yogyakarta, Indonesia. 2020, p. 245-9.

[5] AA Zakri, S Darmawan, J Usman, IH Rosma and B Ihsan. Extract fault signal via DWT and penetration of SVM for fault classification at power system transmission. In: Proceedings of the 2018 $2^{\text {nd }}$ International Conference on Electrical Engineering and Informatics, Batam, Indonesia. 2018, p. 191-6. 
[6] M Raoofat, A Mahmoodian and A Abunasri. Fault location in transmission lines using neural network and wavelet transform. In: Proceedings of the 2015 International Congress on Electric Industry Automation, Shiraz, Iran. 2015.

[7] P Li, H Su, C Wang, Z Liu and J Wu. PMU-based estimation of voltage-to-power sensitivity for distribution networks considering the sparsity of jacobian matrix. IEEE Access 2018; 6, 31307-16.

[8] S Bhamidipati. GPS spoofing detection for PMUs using a hybrid network goals for power grid modernization. 2018.

[9] NM Khoa and DD Tung. Locating fault on transmission line with static var compensator based on phasor measurement unit. Energies 2018; 11, 9-12.

[10] F Zhu, A Youssef and W Hamouda. Detection techniques for data-level spoofing in GPS-based phasor measurement units. In: Proceedings of the 2016 International Conference on Selected Topics in Mobile and Wireless Networking, Cairo, Egypt. 2016.

[11] S Nanchian, A Majumdar and BC Pal. Three-phase state estimation using hybrid particle swarm optimization. IEEE Trans. Smart Grid 2017; 8, 1035-45.

[12] M Salman, M Sarailoo and NE Wu. Fault diagnosis based on partitioned power system models. In: Proceedings of the 2016 Resilience Week, Chicago IL, USA. 2016, p. 83-8.

[13] JW Lee, WK Kim, J Han, WH J and CH Kim. Fault area estimation using traveling wave for wide area protection. J. Mod. Power Syst. Clean Energ. 2016; 4, 478-86.

[14] SS Nagam, E Koley and S Ghosh. Artificial neural network based fault locator for three phase transmission line with STATCOM. In: Proceedings of the 2017 IEEE International Conference on Computational Intelligence and Computing Research, Coimbatore, India. 2017.

[15] U Uzubi, A Ekwue and E Ejiogu. Artificial neural network technique for transmission line protection on nigerian power system. In: Proceedings of the 2017 IEEE PES PowerAfrica, Accra, Ghana. 2017.

[16] AS Altaie and J Asumadu. Fault location using a new composite control technique, multiple classifier, and artificial neural network. In: Proceedings of the 2017 IEEE Texas Power and Energy Conference, College Station TX, USA. 2017.

[17] KN Kumar, K Vijayakumar and C Kalpesh. Virtual energy storage capacity estimation using ANNbased kWh modelling of refrigerators. IET Smart Grid 2018; 1, 31-9.

[18] AA Zakri and S Tua. Recurrent Neural networks to identify fault in transmission line. Tech. Rep. Kansai Univ. 2020; 62, 733-42.

[19] A Azriyenni, MW Mustafa, DY Sukma and ME Dame. Backpropagation neural network modeling for fault location in transmission line $150 \mathrm{kV}$. Indones. J. Electr. Eng. Informat. 2014; 2, 1-12.

[20] MAFC Firdous. Sistem pencarian jarak terdekat menggunakan metode haversine berbasis android. Teknik Informatika 2017; 2017, 1-9.

[21] HA Hassan and M Zellagui. Optimal coordination of directional overcurrent relays using BFOA8PSO algorithm. Electroteh. Electron. Autom. 2015; 63, 116-25.

[22] T Chai and RR Draxler. Root mean square error (RMSE) or mean absolute error (MAE) Arguments against avoiding RMSE in the literature. Geosci. Model Dev. 2014; 7, 1247-50.

[23] M Mahdi and VMI Genc. Artificial neural network based algorithm for early prediction of transient stability using wide area measurements. In: Proceedings of the $20175^{\text {th }}$ International Istanbul Smart Grid and Cities Congress and Fair, Istanbul, Turkey. 2017. p. 1-5. 